\title{
Das Mass der Dinge
}

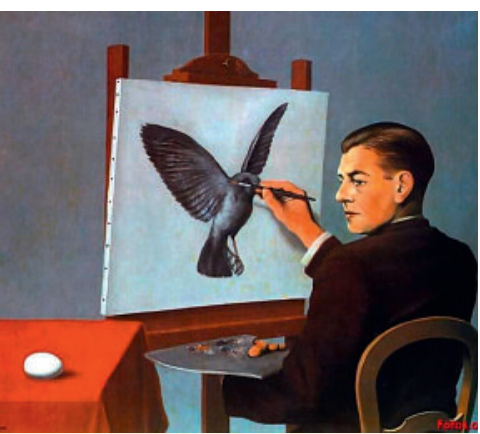

Unser Gehirn erschafft sich seine Welt.

Erhard Taverna
Seit der Industrialisierung expandiert das Universum der Dinge. Darin sind Weihnachten und Neujahr die Tsunamis jener Warenfluten, die unser ganzes Leben bestimmen. Dabei ist nicht immer klar, ob wir die Dinge haben oder ob es sich nicht genau umgekehrt verhält. Zumindest müsste man von einer sehr engen Symbiose ausgehen, sind wir doch selber Körper, den wir als Neugeborener und Säugling zusammen mit der engsten Umgebung schrittweise erfassen und begreifen. Diese Wahrnehmung der Dingwelt zieht lebenslänglich immer weitere Kreise, bis sie aus dem Bewusstsein verschwindet, bis die abgenutzten Wörter den ertaubten Sinnen entsprechen.

\section{Die Philosophie}

Am Anfang des Denkens bestimmen magische und animistische Vorstellungen das Verhältnis. Die belebte und unbelebte Umwelt und die hergestellten Gegenstände führen ein Eigenleben, nehmen Einfluss und sind Schicksal. Im Markenkult der Gegenwart lebt dieser Totemismus ungebrochen weiter. Die Grundlagen der Konsumwirtschaft beruhen auf dem gleichen Fetischismus, den die früheren Ethnologen ausschliesslich den primitiven Kulturen zuschrieben. Böse Zungen behaupten, dass die ganze abendländische Philosophie aus Fussnoten zu Platons Lehre bestünde. Sind die idealen Verkörperungen den fehlerhaften Abbildern übergeordnet, betrachten wir immer nur die Schattenbilder an der Höhlenwand? Eine Auseinandersetzung, die sich vom scholastischen Universalienstreit über die Phänomenologie bis zum Konstruktivismus hinzieht. Einerseits die Nominalisten, die dem Ding die Priorität einräumen, andererseits die Realisten, die den Allgemeinbegriffen den Vorrang überlassen.

Nach den historischen Katastrophen der Moderne haben Romantik und Idealismus einen schweren Stand. Der Fokus richtet sich erneut auf das Phänomen, auf die Sache selbst. Der zerebrale Zugang ist alles, unser Gehirn erschafft sich seine Welt, ausserhalb davon ist für uns nichts erkennbar. Weil das Gegenständliche in der Naturwissenschaft zu verschwinden scheint, sind die Gegenreaktionen umso heftiger. Der Entzauberung im Namen der Rationalität entspricht die Wiederverzauberung durch neue Idol- und Kultformen und das Erstarken religiöser Gewissheiten. Gemäss deren Dogmen sind wir selbst und alles, was uns umgibt, vorbestimmt und unveränderlich.

des choses - Im Namen der Dinge. Frankfurt: Suhrkamp; 1973.

- Kafka F. Die Erzählungen. Zürich: Buchclub Ex Libris.

\section{Die Literatur}

Sie wollte schon immer wissen, was Ding und Un-Ding sei. Ob da nach Eichendorff ein Lied in allen Dingen schläft, ob die Poesie nur eine von vielen Erkenntnisformen ist wie Philosophie oder Mathematik, ob die
Dinge selbstredend sind, so dass die Welt sich selbst durch das Bewusstsein des Menschens schreiben (komponieren oder malen) lässt. Kann der Beobachter mehr als nur die Welt vermessen, oder wird ihm das Ding stets seinen Sinn und sein Wesen verweigern? Der Franzose Francis Ponge (1899-1988) steht beispielhaft für den Versuch, den Eigensinn der einfachsten, am wenigsten mit vorgefassten Meinungen besetzten Gegenstände, etwa eines Kruges, Kieselsteins oder von Moos, mit einer präzisen Sprache auszudrücken. Seine Arbeitsweise, so in seinem bekanntesten Werk «Le parti pris des choses» beschreibt er so: «Ich empfehle jedem die Öffnung innerer Falltüren, eine Reise in die Dichte der Dinge, eine Invasion der Eigenschaften, eine Revolution oder einen Umsturz ...» Das Wort wird durch das Ding von seiner Abstraktheit erlöst, während der Gegenstand durch die semantischen Bezüge seine Bedeutungen offenlegt.

Diese Sprachexperimente haben Jean-Paul Sartre $\mathrm{zu}$ einem langen Kommentar veranlasst und viele Künstler, zum Beispiel Peter Handke, stark beeinflusst. Von einer ganz anderen Seite hat sich Franz Kafka 1916 dem Ding genähert. In seiner Kürzestgeschichte «Die Sorge des Hausvaters» geistert ein sonderbares Wesen, eine schwer beschreibbare Zwirnspule namens «Odradek», durch das Haus. Der Name erklärt nichts. Wenn es einmal lacht, klingt es wie das Rascheln gefallener Blätter. Es ist unsterblich, weil es sich nicht benützen lässt, denn «alles, was stirbt, hat vorher eine Art Ziel, eine Art Tätigkeit gehabt und daran hat es sich zerrieben.» Das Gebilde lässt sich nicht einfangen, es ist da, aber es lässt sich nicht ausmachen, was es ist, es entzieht sich allen Begriffen. Es ist nur verfügbar, wenn wir ein Gedanken-Ding daraus machen, doch dann ist es nur noch Sprache und Vorstellung.

Vermenschlichen wir die Dinge, wenn wir intensiver nach ihren Strukturen suchen? Sartre kritisiert bei Ponge, dass dieser dem Gegenstand etwas einverleibe, das der Aussenwelt gehört, dass er den Mineralien menschliche Verhaltensweisen zuschreibe, weil er den Menschen mineralisieren wolle. Wie kann man sich den Dingen wirklich nähern und doch ein Mensch bleiben, wenn sie doch so ganz anders sind? Wir haben Dinge und wir sind Dinge. Die Spannung dieser Doppelnatur auszuhalten, sie für eine geschärfte Wahrnehmung einzusetzen und die Sprache an diesem Gegensatz zu schärfen, dient unserer eigenen Entwicklung. Dann sind alle Dinge bezeichenbar und real oder zumindest mental «zuhanden», und es gilt vielleicht immer noch der Satz von Protagoras: «Der Mensch ist das Mass aller Dinge, der Seienden, dass sie sind, und der Nichtseienden, dass sie nicht sind.» 